\title{
PROCESOS ETNOPOLÍTICOS DE AUTODETERMINACIÓN Y PERSPECTIVAS DE CONSERVACION MARINA EN RAPA NUI
}

\author{
Ethnopolitical Processes of Self-determination and Prospects
}

for Marine Conservation in Rapa Nui

\author{
XIMENA LAGOS* ${ }^{*}$ BÁRBARA ESCOBAR ${ }^{\star *}$, ANDREA SEELENFREUND***, \\ ALTAIR MAGRI ${ }^{\star \star \star \star *} \&$ ANDRÉS MARÍN ${ }^{\star * \star \star *}$
}

Fecha de recepción: 20 de abril de 2020 - Fecha de aprobación: 05 de octubre de 2020

\section{Resumen}

Este trabajo describe la trayectoria etnopolítica rapanui en su demanda de autodeterminación y autonomía, vinculándola a procesos actuales de conservación de recursos naturales, como el de la creación del área costera-marina protegida de múltiples usos. Se identificaron hitos mediante revisión bibliográfica y entrevistas en profundidad a actores claves, tales como el Acuerdo de Voluntades, los movimientos anticolonialistas, el estatuto especial de administración y las iniciativas en conservación marina, que denotan los conflictos con el Estado chileno y la búsqueda de reconocimiento y autodeterminación. Observamos que la autonomía como proceso se profundiza en los últimos diez años, al utilizar los mecanismos institucionales-legales y administrativos del Estado chileno para transitar a formas propias de gestión territorial. En ese sentido, afirmamos que la creación del área costera-marina protegida de múltiples usos de Rapa Nui es más bien parte de un camino de autodeterminación territorial a escala marina que de una estrategia de conservación.

Palabras clave: autodeterminación; conservación; gestión marina; etnopolítica.

\section{Abstract}

The present article describes the ethnopolitical route taken by the Rapa Nui community on its path towards self-determination and autonomy, linking it to current processes for the conservation of natural resources of the island, in particular the creation of the coastal-marine protected area of multiple uses. Through an ethnographic approach, milestones such as the Treaty or "Acuerdo de Voluntades", anti- colonialist movements, special statute of administration and marine conservation initiatives were identified, that denote conflicts with the Chilean State and the search for recognition and self-determination in each of them. In this sense, we visualize the search for autonomy as a process that in the last 10 years has expanded, and in which the Chilean State's own institutional-legal and administrative mechanisms have been used as a vehicle. In this sense, we state that the process surrounding the creation of the coastal-marine protected area is to be understood primarily as a path of territorial self-determination on the marine scale, rather than as a conservation strategy.

Keywords: self-determination; conservation; marine-management; ethnopolitics.

\footnotetext{
* Antropóloga. Doctoranda en Ciencias Políticas (FCS-UDELAR). Profesora en Centro Universitario Regional del Este, Universidad de la República, Rocha, Uruguay. Correo-e: xlagos@cure.edu.uy

** Antropóloga Social. Investigadora independiente. Montevideo, Uruguay. Correo-e: bescobara@gmail.com

*** Dra. en Arqueología. Profesora titular, Escuela de Antropología, Universidad Academia de Humanismo Cristiano, Santiago, Chile. Correo-e: aseelenfreund@academia.cl

**** Dra. en Ciencias Políticas. Profesora en Departamento de Ciencias Políticas, Universidad de la República, Montevideo, Uruguay. Correo-e: altair.magri@cienciassociales.edu.uy

***** Dr. en Ciencias de la Sostenibilidad. Investigador en Centro de Estudios del Desarrollo Regional y Políticas Públicas, Universidad de Los Lagos, Osorno, Chile. Correo-e: andres.marin@ulagos.cl
} 


\section{Introducción}

La creación de áreas de conservación y manejo ha sido una herramienta de la política ambiental a nivel mundial en los últimos veinte años. En Latinoamérica, los esfuerzos gubernamentales se han enfocado en desarrollar diferentes esquemas de protección de la biodiversidad o de manejo sustentable de los recursos, como en el caso pesquero artesanal (Begossi, 2010). En la década de 1970 comienza el proceso de institucionalización mundial del tema ambiental, pero es en la Conferencia de las Naciones Unidas sobre Ambiente y Desarrollo (RIO 92), con la firma del Convenio sobre Diversidad Biológica (CDB), que se crea un marco político vinculante para la conservación a partir del cual se fomenta la creación de mecanismos de protección y manejo de la biodiversidad mediante las áreas protegidas tanto continentales como marinas (De Santo, 2013).

Las áreas protegidas son herramientas que permiten trabajar a escala local y elaborar estrategias de conservación in situ de especies y ecosistemas (Secretaría del Convenio sobre la Diversidad Biológica, 2004). Sin embargo, la implementación de áreas protegidas es un proceso social complejo que envuelve aspectos socioinstitucionales y ecológicos y en el que ha prevalecido el modelo "desde arriba" (top-down), aunque, paulatinamente, se avanza hacia generar espacios de integración de actores con la incorporación del concepto de gobernanza como pilar fundamental de la conservación (Oyanedel, Marín, Castilla \& Gelcich, 2016).

Las zonas costeras y marinas pueden ser vistas como una categoría de intervención, socioinstitucional y ecológica, lo que las convierte en un objeto de decisión y acción pública (Mazé, Dahou, Ragueneau, Danto, Mariat-Roy \& Raimonet, 2017). Tal como señala Pahl-Wostl (2009), "[l]a gestión de recursos es un proceso político y la implementación de todas las políticas es en cierta medida un experimento" (p. 355). En este sentido, es necesario considerar los impactos que genera a escala local la implementación de áreas protegidas, sobre todo en lo político y cultural, referidas, por ejemplo, a la autodeterminación, la soberanía y la identidad étnica de las comunidades. Dentro de los impactos negativos, se encuentran los desplazamientos, la restricción, la reducción o la pérdida de derechos de acceso a recursos, el aumento de conflictos sociales, la inequidad en la distribución de las áreas, la pérdida de soberanía alimentaria y territorial, entre otros (Bennet \& Dearden, 2014; West, Igoe \& Brockington, 2006).

Esto último ha implicado la resistencia a las áreas protegidas de comunidades locales e indígenas, tanto en poblaciones del Pacífico (Mawyer \& Jacka, 2018) como en Latinoamérica, donde el proceso de construcción de las áreas marinas protegidas (AMP) se ha desarrollado en el marco de economías neoliberales con democracias con escasos espacios de participación y gobernanza (Zubriggen, 2011). Las AMP son una respuesta a los acuerdos internacionales adquiridos por los Estados nacionales en materia de conservación (De Santo, 2013). Sin embargo, al mismo tiempo, comunidades indígenas han apostado a la creación de AMP utilizando los mecanismos institucionales de los Estados-nación para asegurar la sustentabilidad del mar, detener el avance del modelo de desarrollo imperante (Araos et al., 2020b) y asegurar la soberanía de los territorios ancestrales. 
La soberanía, entendida "no sólo como un estatus político sino que como una forma de vivir en relación con la tierra y otros" (GoodyearKa'o pua, 2015, en Mawyer \& Jacka, 2018, p. 239), entra, en muchos casos, en contradicción con esquemas de AMP promovidos por los gobiernos, las agencias internacionales o las organizaciones no gubernamentales (ONG), que generan nuevas estructuras de administración, con mecanismos de gobernanza multinivel o de alta dependencia del gobierno central. Además, estos modelos de conservación pueden resultar exógenos, occidentalizados y con procedimientos estandarizados que homogeneizan las prácticas culturales locales en su vínculo con los recursos marinos, sin considerar la heterogeneidad de las cosmovisiones indígenas (West et al., 2006; Bennet \& Dearden, 2014). Frente a esto, el derecho a la autodeterminación busca dar legitimidad a los pueblos indígenas en cuanto a gestión política, económica y sociocultural (Bartolomé, 1997), reconociendo su capacidad para generar un proyecto propio de gestión territorial. Para Díaz-Polanco (1999), el proyecto autonómico busca un reconocimiento de los derechos políticos y culturales, e implica el ejercicio de gobernarse a sí mismo dentro del marco estatal, donde las acciones colectivas son reconocidas y sostenidas legalmente por parte de los Estados nacionales.

En última instancia, la soberanía y la conservación tienen que ver fundamentalmente con el control de dimensiones humanas y naturales que se acoplan y retroalimentan entre sí (Mawyer \& Jacka, 2018). En términos de control territorial, las AMP también pueden verse como mecanismos de acaparamiento del océano (Bennet, Govan \& Satterfield, 2015), sobre todo cuando estas áreas siguen repro- duciendo modelos colonialistas en sus procesos de implementación, con los que se despoja finalmente a las comunidades de los derechos de uso y autodeterminación sobre los territorios (De Santo, 2013). Pero al mismo tiempo, las AMP pueden ser, para los pueblos indígenas, una respuesta colectiva para proteger modos de vida, prácticas culturales y formas de relacionamiento de las comunidades con y en la naturaleza (Araos, Catalán, Álvarez, Núñez, Brañas \& Riquelme, 2020a).

En el presente trabajo presentamos el caso de la creación del área marina costera de múltiples usos de Rapa Nui como un caso de estudio que vincula procesos políticos autonómicos con control espacial de un área marina. Rapa Nui (Isla de Pascua) es un territorio insular que, si bien está ubicado en el Pacífico y con una historia cultural ligada a las sociedades de Oceanía, es administrado por un Estado latinoamericano. Como en otras islas del Pacífico, se presenta en ella una larga historia de colonialismo, el cual subsiste hasta hoy en las políticas públicas (Delsing, 2017). En esta historia existen hitos en los que la demanda reivindicativa de autodeterminación territorial se mantiene como una constante. El territorio, el tiempo y el espacio se conjugan y se dotan de significación y sentires que dan sustento a la memoria histórica de la sociedad y es en ellos donde se enraíza la identidad cultural (Bartolomé, 1997). En la cultura rapanui, el territorio marino, el maritorio (Álvarez, Ther-Ríos, Skewes, Hidalgo, Carabias \& García, 2019), adquiere una significación particular porque conecta las identidades locales con la cultura polinésica, en la que el océano es la base de la cosmovisión, el comienzo y la razón de toda la vida social y natural (Hau'ofa, 1994; D’Arcy, 2006). 
Las culturas polinésicas se han desarrollado $y$ organizado socialmente en torno al mar y sus recursos. En Rapa Nui, el manejo de estos ha estado caracterizado por elementos culturales propios, tales como el tapu, en los que se establecen restricciones estacionales a la extracción de recursos (Aburto, Gaymer, Haoa \& González, 2015). Estas formas tradicionales se enfrentan a los procesos de modernización tecnológica y de gestión propios de miradas continentales que difieren en sus prácticas, conocimientos y cosmovisiones a los del pueblo rapanui (Aburto \& Gaymer, 2018). Junto a esto, en Rapa Nui se observa una importante disminución de las especies en las últimas décadas, tanto de las de aguas abiertas como de las de pesca costera (Aburto et al., 2015).

El deterioro de los ecosistemas ha desencadenado acciones de conservación de los recursos marinos desde lo local y lo internacional, sin embargo, la conservación tiene muchas dimensiones (culturales, económicas, político-institucionales y ecológicas) por lo que es necesario una planificación estratégica de conservación y una planificación espacial marina, lo que no siempre tiene que ver con asegurar la sustentabilidad de los ecosistemas (De Santo, 2013). Proteger las especies, los ecosistemas y los servicios que brindan a las sociedades humanas se convierte en una tarea que requiere ciencia interdisciplinaria y muchas capas de información a múltiples escalas (Pressey, Cabeza, Watts, Cowling \& Wilson, 2007).

En particular, el estudia de los procesos de conservación desde las ciencias sociales ha buscado "desnaturalizar la naturaleza" (Santos, 2010, p. 14), es decir, develar el entramado de relaciones y significaciones de la esfera social que determinan las relaciones humano-natura- leza. Esto resulta clave para entender y mejorar las políticas, las prácticas y los resultados de la conservación y promover enfoques de manejo y relación con los recursos naturales desde una perspectiva situada.

El objetivo de este trabajo es mostrar cómo en Rapa Nui la conservación de los recursos costeros es parte de un proceso social que excede a la gestión de los ecosistemas. Se reconocen respuestas etnopolíticas a iniciativas foráneas que enarbolan una bandera ambiental. En una mirada diacrónica-sincrónica situamos este proceso dentro de un continuo de hitos de vinculación con el Estado, en los que la demanda de reconocimiento y autodeterminación se manifiesta y la búsqueda de autonomía se hace presente. Analizamos la conservación marina en Rapa Nui, en específico la creación de su reciente AMP, como parte de una trayectoria de procesos etnopolíticos de reivindicación étnico-territorial. Para esto, describiremos primero hitos que resultan claves en el proceso de demanda de autodeterminación del pueblo rapanui, desde la anexión de la isla a Chile hasta el Estatuto Especial de Administración. Posteriormente, abordaremos las actuales iniciativas de manejo de recursos marinos desde sus dinámicas socioinstitucionales y la relación de estos procesos con la demanda de autodeterminación del pueblo rapanui.

En este sentido, enmarcamos las iniciativas de conservación marina en las propuestas teóricas de Delsing (2017) en torno a la politización de la identidad cultural rapanui que plantea que las expresiones culturales (tal como es la fuerte conexión al maritorio) tienen una faceta política, ligada a una estrategia vinculada a la descolonización y la lucha por la autodeterminación política y administrativa. Por otra parte, 
tomamos el concepto de Bartolomé (2002) de cultura de la resistencia para referirnos a la lucha a favor del conjunto de referentes culturales que la sociedad rapanui ha asumido como fundamentales para su configuración identitaria. Así, frente a las iniciativas foráneas de conservación (a partir de ONG o del Estado chileno) y su institucionalización a través de esquemas de protección marina, se levanta en Rapa Nui una cultura de resistencia para generar una rapanuización de la conservación. Esta se expresa en la apropiación de estos procesos, encauzándolos en la recuperación del control a través de la administración del océano, el vaikava, y significándolos como parte de las luchas reivindicativas del pueblo rapanui.

\section{Métodos}

El trabajo que aquí presentamos se enmarca dentro de las metodologías cualitativas, particularmente en el enfoque etnográfico y el análisis bibliográfico. Esta investigación se ha realizado en dos etapas, separadas por un largo intervalo temporal. Nuestro primer acercamiento a la problemática data del año 2005, cuando realizamos el primer trabajo de campo (de noviembre 2005 a marzo 2006). Esa instancia se focalizó en las percepciones de la comunidad e instituciones relacionadas al proyecto de Estatuto Especial de Autonomía Administrativa promovido por el gobierno. La segunda etapa se refiere al trabajo de campo realizado entre agosto de 2018 y marzo de 2019, que estuvo centrado en levantar información sobre la creación y la gestión costero-marina del área marina protegida de múltiples usos (AMCP-MU).

En esta segunda etapa se realizaron entrevistas a miembros de la comunidad, actores institucionales relacionados directa e indirectamente con la gestión costero-marina y a actores institucionales involucrados de la Subsecretaría de Pesca y del Ministerio de Medio Ambiente. Se llevaron a cabo entrevistas junto con observación participante en reuniones de la Comisión de Desarrollo de Isla de Pascua (CODEIPA) y otras actividades coordinadas por la organización Te Mau o Te Vai Kava.

Al ser una sociedad pequeña, casi todos los habitantes de la isla se encuentran ligados a una institución o grupo, lo que nos ayudó a reconocer los discursos respectivos de cada área. Cada habitante del territorio insular interviene, en cierto modo, en el acontecer social, político y económico de Rapa Nui y, a su vez, es afectado por él. Cada individuo es de suma importancia dentro de la sociedad isleña, ya que cada acción genera una "bola de nieve". La muestra seleccionada de Stakeholders representa la mayor parte de las instituciones en el territorio insular, así como también personalidades reconocidas dentro de la comunidad por su discurso y acciones. En algunos casos forman parte de instituciones legitimadas tanto por el gobierno central como por la comunidad insular (Parlamento Rapa Nui, CODEIPA, Consejo Municipal, entre otros), por lo que el discurso implícito en cada caso es reconocible.

Realizamos 23 entrevistas en total, de las cuales 13 corresponden a entrevistas en profundidad con los actores seleccionados (seis miembros electos del Consejo del Mar, dos técnicos asesores, dos representantes de la CODEIPA, un técnico asesor de este mismo organismo y dos representantes de instituciones) y nueve entrevistas abiertas (tres técnicos de la Subsecretaría de Pesca y Acuicultura [SUBPESCA], dos técnicos del Ministerio 
de Medio Ambiente, dos académicos y dos miembros vinculados al Parlamento Rapanui).

En todas las etapas se aplicaron entrevistas abiertas y semiestructuradas a miembros de la comunidad y funcionarios de las principales instituciones presentes en el territorio Rapa Nui. Las entrevistas contenían preguntas abiertas sobre los hitos de construcción del área protegida, la vinculación del área marina con el Parque Nacional y de estos espacios con la demanda autonómica. La información cualitativa fue organizada y analizada a través del software ATLAS.ti 8 (Scientific Software Development $\mathrm{GmbH}$ ).

\section{Resultados}

\section{Trayectorias etnopolíticas en Rapa Nui}

Comenzamos analizando momentos históricos o "estructuras de coyunturas", como plantea Sahlins (1997, p. 14), es decir, "la realización práctica de las categorías culturales en un contexto histórico específico". Dichas categorías culturales están relacionadas con la búsqueda constante del pueblo rapanui de reconocimiento por parte del Estado chileno no solo de sus diferencias culturales, sino del rol que este asumió desde la firma del Tratado o "Acuerdo de Voluntades" en 1888 (ICVHNT, 2003).

De acuerdo con la estructura política de una cultura polinésica, los jefes chilenos traerían bienes o cargo (Castro, 2007), lo que se traduciría en poder simbólico para los jefes rapanui, quienes veían en las autoridades chilenas la encarnación terrestre de una poderosa divinidad (véase Sahlins, 1997 y Tcherkézoff, 1997, 2004) que les permitía acrecentar su poder y, por ende, también su mana. Tradicionalmente, a través del cargo se espera una mejoría global en el nivel de vida. Bajo esta lógica podemos ver la autonomía también como cargo: la autonomía trae bienestar, desarrollo y mana al rapanui. Los discursos de identidad cultural en el Pacífico contemporáneo son derivados, en gran mayoría, según Keesing (2000), de la creación mítica. Estos provienen del pasado precolonial pero son readquiridos y resignificados como medio de legitimación identitaria y levantamiento para nuevos movimientos socioétnicos de lucha contra las formas poscoloniales. La trayectoria atemporal de estas reivindicaciones las convierten en una demanda ancestral ${ }^{1}$ basada en el derecho a decidir por sí mismos el destino de su propia tierra, mar y cultura, es decir, su autodeterminación.

A continuación, analizaremos diferentes hitos que nos permiten entender los puntos en que acontecimiento y demanda de autodeterminación se hacen presentes (Tablas 1-3). Describiremos sucesos, desde el Acuerdo de Voluntades hasta la toma del Parque, que nos parecen relevantes para visualizar cómo se enmarcan las relaciones con el Estado chileno y las respuestas emergidas desde el pueblo rapanui, en específico respecto de las formas de autodeterminación. 
Tabla 1. Principales hitos históricos en las demandas de autodeterminación en Rapa Nui (1888-1964)

\begin{tabular}{|c|c|c|c|}
\hline HITO & FECHA & DESCRIPCIÓN & REFERENCIAS \\
\hline Acuerdo de Voluntades & 1888 & $\begin{array}{l}\text { El } 9 \text { de septiembre de } 1888 \text { se firma en la } \\
\text { isla el documento llamado por el Estado } \\
\text { chileno "Anexión de Rapa Nui" y "Acuerdo } \\
\text { de Voluntades" por el pueblo rapanui. }\end{array}$ & $\begin{array}{l}\text { ICVHNT, } 2003 \\
\text { Mendoza, } 2004 \\
\text { Stambuk, } 2010 \\
\text { Fuentes, } 2013\end{array}$ \\
\hline $\begin{array}{l}\text { Sucesión de } \\
\text { arrendamientos para } \\
\text { explotación ganadera }\end{array}$ & $\begin{array}{l}1872-1876 \\
1877-1888 \\
1888-1892 \\
1895-1903\end{array}$ & $\begin{array}{l}\text { Dutrou Bornier } \\
\text { Sucesión Brander y Salmon } \\
\text { Hermanos Toro } \\
\text { Arrendamiento de la isla a Enrique Merlet². } \\
\text { D. L. № } 1.230 \text {. }\end{array}$ & $\begin{array}{l}\text { Stambuk, } 2010 \\
\text { Fuentes, } 2013 \\
\text { ICVHNT, } 2003\end{array}$ \\
\hline $\begin{array}{l}\text { Compañía Explotadora } \\
\text { de Isla de Pascua }\end{array}$ & $1903-1953$ & $\begin{array}{l}\text { Formada por la asociación de Enrique } \\
\text { Merlet con la empresa angloescocesa } \\
\text { Williamson Balfour. }\end{array}$ & Fuentes, 2013 \\
\hline $\begin{array}{l}\text { Levantamiento de María } \\
\text { Anata }\end{array}$ & 1914 & $\begin{array}{l}\text { Movimiento de reivindicación política, } \\
\text { autodeterminación y autonomía } \\
\text { comunitaria rapanui. }\end{array}$ & Castro, 2007 \\
\hline $\begin{array}{l}\text { Fin administración } \\
\text { Compañía Explotadora } \\
\text { de Isla de Pascua }\end{array}$ & 1953 & Inicio administración Armada de Chile. & $\begin{array}{l}\text { ICVHNT, } 2003 \\
\text { Fuentes, } 2013\end{array}$ \\
\hline Movimiento Alfonso Rapu & 1964 & $\begin{array}{l}\text { Movimiento anticolonialista que consigue } \\
\text { la creación del municipio y la ciudadanía } \\
\text { chilena con la Ley Pascua } 16.441 \text { (1966). }\end{array}$ & $\begin{array}{l}\text { Grifferos, } 1995 \\
\text { ICVHNT, } 2003\end{array}$ \\
\hline
\end{tabular}

Planteamos el Acuerdo de Voluntades como el punto de partida de las relaciones entre Rapa Nui y Chile a partir del cual se establecen las bases del diálogo entre ambos. En la versión escrita en tahitiano/rapanui, se concedía al Estado chileno el usufructo de la tierra, pero no la propiedad de la tierra en sí. Sin embargo, el texto en español no hace mención a la propiedad de la tierra, sino a la cesión de soberanía. Las malas traducciones e interpretaciones erróneas (Hito, 2004) están en la base de estas narrativas conflictivas. Por el lado chileno se pensaba en una soberanía sin reserva, la que se contraponía con la idea de abundancia que sostenían los jefes rapanui relacionada directamente con el mana y la ritualidad apropiada, la cual aseguraría la llegada y la permanencia del bienestar al territorio. Sin embargo, la no ratificación del Acuerdo por el Estado chileno (Mendoza, 2004) constituye la base discursiva de las reivindicaciones para los rapanui. La discusión sobre la interpretación del Acuerdo se focaliza en el territorio o kainga. Para el pueblo rapanui, el territorio está íntimamente ligado a su cosmovisión y es en él donde lo político y lo cultural se hacen evidentes, en el discurso y en la práctica (Delsing, 2017). 
Posterior a la firma del Acuerdo, en 1903, el Estado chileno arrendó el territorio insular a la Compañía Explotadora de Isla de Pascua. Esta transformó a la isla en una estancia ganadera, despojó a los rapanui de sus tierras y de su vínculo con el mar a través de la pesca y los convirtió en trabajadores esclavos de la compañía con niveles de explotación extremos (ICVHNT, 2003; Mendoza, 2004; Stambuk, 2010). Bajo estas condiciones se desarrolló un movimiento conducido por la catequista María Anata, que utilizó elementos religiosos por encontrarse en torno a la misión católica. Este movimiento se opuso al régimen de explotación social, cultural y económica del pueblo y el territorio Rapa Nui. Sin embargo, su objetivo final era la reivindicación política. Como señala Castro (2007):

El movimiento de Anata buscaba la reinstauración de un orden moral tradicional, que había sido lesionado por la compañía y que se inspiraba en el modelo comunitario [...] se trataba de un esfuerzo basado en verdad y justicia [...] un movimiento que concibió el problema del poder fundiendo la soberanía en lo sagrado. (p. 191)

El término del contrato del Estado de Chile con la Compañía Explotadora dio paso a la administración de la Armada (véase Tabla 1). Los rapanui, sin embargo, siguieron sujetos a condiciones de explotación y violencia, pues se mantuvieron los castigos corporales, la restricción de circular por la isla y la prohibición de pescar (Grifferos, 1995). Estas situaciones llevaron a un punto de agitación social que motivó a Alfonso Rapu a enviar una carta al presidente Frei Montalva en la que explicaba la situación de opresión en que se encontraba su pueblo. Esto desencadenó un movimiento que logró la libre circulación por la isla y la realización de elecciones, con la designación de Alfonso Rapu como primer alcalde (Grifferos, 1995).
En este proceso de reivindicación, "[l]os rapanui se apropiaron de los elementos centrales que daban cuerpo a los procesos de homogenización, introduciéndolos en una innovadora reformulación de la tradición" (Grifferos, 2003, p. 43). Así, a través de la apropiación y la legitimación de las estructuras continentales, como el municipio, los rapanui buscaron crear nuevas formas de autoridad emanadas desde sus propias aspiraciones. En ese contexto, lograron ser considerados ciudadanos con el pronunciamiento de la llamada Ley Pascua, con la que la comunidad rapanui fue integrada, con todos los derechos civiles, al Estado chileno. Como recuerda Alfonso Rapu,

Del 66 al 2006 hay diferencias; antes éramos prisioneros, encerrados, sin profesiones, en el abandono, una vez al año venía un barco a abastecer, la Armada manejaba el sistema. Ha habido un gran desarrollo en poco tiempo. Se creó el departamento de Isla de Pascua y entraron diferentes servicios públicos, la gente empezó a salir de la isla, hubieron beneficios, se abrió el comercio y las escuelas. (A. Rapu, diciembre 2006)

En 1979, bajo la dictadura militar, se dictó un decreto que modificó la Ley Pascua con el objetivo de regularizar la propiedad en la isla, otorgando títulos de dominio a los poseedores regulares (Astudillo, 2018), lo que generó conflictos dentro de la comunidad rapanui por no respetar los límites ancestrales. Frente a esta coyuntura se reconstituyó el Consejo de Ancianos con el fin de resguardar y resistir frente a la asimilación de las comunidades indígenas, que era el objetivo de dicha ley (Delsing, 2017). 
Tabla 2. Trayectoria histórica de demandas rapanui contra el Estado chileno (1993-2007)

\begin{tabular}{|c|c|c|c|}
\hline HITO & FECHA & DESCRIPCIÓN & REFERENCIAS \\
\hline $\begin{array}{l}\text { Promulgación de la Ley } \\
\text { Indígena } N^{\circ} 19.253\end{array}$ & 1993 & $\begin{array}{l}\text { Se crea la Comisión de Desarrollo } \\
\text { de Isla de Pascua (CODEIPA), } \\
\text { conformada por representantes } \\
\text { de instituciones gubernamentales, } \\
\text { alcalde y representantes electos de } \\
\text { la etnia. }\end{array}$ & $\begin{array}{l}\text { Astudillo, 2018, } \\
\text { ICVHNT, } 2003\end{array}$ \\
\hline $\begin{array}{l}\text { Comisión de Verdad y Nuevo } \\
\text { Trato }\end{array}$ & 2003 & $\begin{array}{l}\text { Se propone una nueva organización } \\
\text { administrativa para Rapa Nui. }\end{array}$ & $\begin{array}{l}\text { Astudillo, } 2018 \\
\text { Delsing, } 2017 \\
\end{array}$ \\
\hline $\begin{array}{l}\text { Creación del Grupo de } \\
\text { Personalidades }\end{array}$ & 2004 & $\begin{array}{l}\text { Elaboración del Estatuto Especial } \\
\text { de Administración Insular. }\end{array}$ & $\begin{array}{l}\text { Lagos \& Escobar, } \\
2009\end{array}$ \\
\hline $\begin{array}{l}\text { Creación de Territorios } \\
\text { Especiales }\end{array}$ & 2007 & $\begin{array}{l}\text { Promulgación del Estatuto Especial } \\
\text { de Administración Insular. }\end{array}$ & $\begin{array}{l}\text { Delsing, } 2017 \text {, } \\
\text { Lagos \& Escobar, } \\
2009\end{array}$ \\
\hline
\end{tabular}

La demanda de autonomía se volvió a articular frente a la promulgación de la Ley Indígena № 19.253. En esto es clave la CODEIPA, órgano de toma de decisiones en torno a la propiedad de la tierra y la elaboración de planes de desarrollo para la isla. A partir de la década de 2000 , se observan profundos cambios a escala institucional en Rapa Nui, en particular desde el punto de vista de la movilización local, con más participación en las esferas políticas y administrativas, aspecto en el que la CODEIPA jugará un rol clave (Delsing, 2017; Astudillo, 2018). Delaire (2018), señala que el Consejo de Ancianos, durante la década de 1990, se ajustó a la visión de transición política propia de ese tiempo, lo que implicó que no hubiera avances significativos en una administración propia del territorio insular por parte del pueblo rapanui. El trabajo en torno al informe para la Comisión de Verdad Histórica y Nuevo Trato (CVHYNT), tuvo una alta repercusión etnopolítica al interior de la etnia, en la relectura de su propia historia y sus formas de administración. Esto fue apoyado por el Relator Especial de la ONU, Rodolfo Stavenhaggen ${ }^{3}$, quien informó que la realización de un nuevo proyecto de administración debiera contener garantías de protección de los derechos del pueblo rapanui sobre sus tierras y recursos y el respeto a su organización social y vida (Stavenhaggen, 2004) ${ }^{4}$.

La promulgación de los Territorios Especiales en 2007 reabrió el debate acerca de la autonomía de Rapa Nui, de los alcances e implicancias de esta, de los modelos existentes, de la cuestión de la independencia y las conexiones con los procesos de descolonización en el resto de la Polinesia. Sin embargo, el gobierno puso énfasis en el carácter administrativo de esta nueva política, insertándola en el contexto de descentralización del Estado, con lo cual la desligó de cualquier componente étnico (Lagos \& Escobar, 2009).

En 2010 se implementó, por primera vez, una instancia consultiva frente a la aprobación 
del Convenio 169 de la Organización Internacional del Trabajo (OIT) el año anterior (véase Tabla 3). La consulta surgió frente a la ocupación de diversos puntos en la isla por parte de la comunidad, que reivindicaba la propiedad ancestral de territorios que estaban en manos del fisco (Fuentes, 2013). Esta consulta no tuvo gran participación de la comunidad por considerar el proceso poco transparente y los resultados obtenidos no fueron bien recibidos por ella. A partir de esta instancia, una serie de consultas públicas (Tabla 3 ) cambiarían la forma de tomar decisiones en la isla.

Tabla 3. Principales hitos históricos en las demandas de autodeterminación en Rapa Nui (2009-2016).

\begin{tabular}{|c|c|c|c|}
\hline HITO & FECHA & DESCRIPCIÓN & REFERENCIAS \\
\hline $\begin{array}{l}\text { Entrada en vigencia del } \\
\text { Convenio } 169 \text { de la OIT. } \\
\text { Se establece el "derecho } \\
\text { a la consulta previa". }\end{array}$ & 2009 & $\begin{array}{l}\text { El gobierno debe asegurar un proceso de } \\
\text { consulta frente a la dictación o cambio de } \\
\text { medidas legislativas o administrativas que } \\
\text { afecten a la comunidad. }\end{array}$ & Astudillo, 2018 \\
\hline $\begin{array}{l}\text { Movilización por la } \\
\text { reivindicación de los } \\
\text { terrenos de la familia } \\
\text { Hito. }\end{array}$ & 2010 & $\begin{array}{l}\text { Toma del hotel Hanga Roa y movilizaciones } \\
\text { en la plaza de la Gobernación. }\end{array}$ & $\begin{array}{l}\text { Fuentes, } 2013 \\
\text { Delsing, } 2017 \\
\text { Astudillo, } 2018\end{array}$ \\
\hline $\begin{array}{l}\text { Primera consulta sobre } \\
\text { migración, estatuto } \\
\text { administrativo, plan de } \\
\text { desarrollo y tierras. }\end{array}$ & 2010 & $\begin{array}{l}\text { Sus resultados no fueron legitimados por } \\
\text { la comunidad por no presentar medidas } \\
\text { concretas, además de no ser considerados } \\
\text { para el manejo del Parque. }\end{array}$ & $\begin{array}{l}\text { Fuentes, } 2013 \\
\text { Delsing, } 2017 \\
\text { Astudillo, } 2018\end{array}$ \\
\hline $\begin{array}{l}\text { Consulta } \\
\text { Coadministración del } \\
\text { Parque Nacional Rapa } \\
\text { Nui. }\end{array}$ & 2015 & $\begin{array}{l}\text { No fue validada por la comunidad por no } \\
\text { asegurar la total administración del parque. } \\
\text { De este proceso se desprende el convenio } \\
\text { entre la CONAF y Ma'u Henua }\end{array}$ & Astudillo, 2018 \\
\hline $\begin{array}{l}\text { Consulta sobre el } \\
\text { Estatuto Especial. }\end{array}$ & 2016 & $\begin{array}{l}\text { Se trabajó sobre la Ley de Residencia, } \\
\text { Gestión Marina y Patrimonio Arqueológico } \\
\text { para una nueva administración desde la isla. }\end{array}$ & Astudillo, 2018 \\
\hline Dictación Ley N 21.070. & 2016 & $\begin{array}{l}\text { Ley que regula la residencia, la } \\
\text { permanencia y el traslado hacia y desde el } \\
\text { territorio especial de Isla de Pascua }\end{array}$ & Astudillo, 2018 \\
\hline $\begin{array}{l}\text { Creación del } \\
\text { Servicio Nacional de } \\
\text { Biodiversidad y Áreas } \\
\text { Protegidas. }\end{array}$ & 2016 & $\begin{array}{l}\text { Reconoce las facultades de la CODEIPA en } \\
\text { relación con la gestión del Parque Nacional } \\
\text { Rapa Nui y las áreas marinas. }\end{array}$ & Astudillo, 2018 \\
\hline
\end{tabular}

En el año 2016, a partir de una nueva consulta pública en torno al Estatuto Especial, se generaron mesas de trabajo temáticas sobre tierras, migración, parque y áreas marinas organizadas principalmente por la CODEIPA (véase Tabla 3). Respecto a las áreas marinas, se buscaba incluir en el Estatuto Especial la creación de un área de conservación y un régimen especial de administración del mar, el reconocimiento de las prácticas culturales y el derecho exclusivo de los recursos vivos y no vivos para el pueblo rapanui, la administración local, la prohibición de pesca industrial, la regulación y la fiscalización a través de la SUBPESCA y el Servicio Nacional de Pesca y Acuicultura (SERNAPESCA) (Astudillo, 2018). Sin embargo, el proceso de 
votación y una nueva propuesta de Estatuto no se concretaron por discrepancias entre los representantes de la etnia y el gobierno: "El Estatuto no seguimos porque no ofrece ni la mínima garantía de lo que solicitamos y ahí retrocedemos" (B. N., marzo 2019).

A partir de entonces, la estrategia llevada por la CODEIPA es que cada tema de interés territorial se transforme en iniciativas abordadas independientemente. En este sentido, el Informe del International Work Group for Indigenous Affairs (2012) da cuenta de las respuestas insuficientes del Estado chileno:

A este respecto hemos sido testigos de las infructuosas demandas del pueblo rapanui por obtener el reconocimiento de su derecho al autogobierno, por medio de instituciones propias, que permitan implementar las prioridades de desarrollo que definan como pueblo, lo que se ha planteado por la vía de reconocer un "Estatuto Especial" a la Isla de Pascua (p. 17).

La consulta pública (Tabla 3) por la creación del Servicio Nacional de Biodiversidad y Áreas Protegidas resulta relevante dado que las negociaciones de la CODEIPA con el Estado permitieron que se incluyera una indicación que diera continuidad al proceso del Parque Nacional Rapa Nui (PNRN), lo que reafirmó a Rapa Nui como un territorio especial en las formas de representación del pueblo rapanui en la gestión (y coadministración) de áreas protegidas, como el PNRN y el AMCP-MU.

Finalmente, a modo de síntesis, podemos decir que las trayectorias aquí planteadas nos muestran un proceso paulatino, pero sistemático, de reivindicación territorial frente al colonialismo estatal. El cambio más significativo comenzó con la creación de la CODEIPA, la cual, a través del tiempo, incrementó su capacidad de agencia con el Estado para generar transformaciones en la isla, al ser legitimada por la comunidad y por las instituciones con las que debió enfrentarse. Esto es resultado tanto del cambio generacional de los comisionados rapanui, el apoyo técnico, pero también la memoria histórica, donde cada hito y enfrentamiento con el Estado significó un aprendizaje que posicionó a la sociedad rapanui para la defensa de sus bienes naturales, como veremos a continuación.

En 2016, la isla se vio envuelta en varios procesos políticos de decisión interna para avanzar en la propuesta del Estatuto Especial, entre ellos, la Ley de Residencia y la consulta en torno al propio Estatuto. Como parte de la discusión y propuesta de Estatuto que trabajó la CODEIPA, una de sus subcomisiones abordó la conservación del mar. También se trató en los talleres participativos de la etapa de consulta (ver Tabla 3). Este proceso concluyó con una propuesta para ser incluida en el Estatuto Especial, la cual se enfocó en la creación de un área de conservación y un régimen especial de administración del mar, el reconocimiento de las prácticas culturales y el derecho exclusivo de los recursos vivos y no vivos para el pueblo rapanui, su administración local, la prohibición de pesca industrial y la regulación y la fiscalización a través de SUBPESCA y SERNAPESCA (Astudillo, 2018).

\section{Conservación y manejo en Rapa Nui}

Un lugar particular dentro de los procesos de reivindicación en Rapa Nui es el de la conservación y la gestión de los recursos naturales y culturales. En este sentido, para comprender cómo se articula la conservación en las trayectorias etnopolíticas antes mencionadas, describiremos brevemente algunos aspectos 
del proceso ocurrido con el PNRP que mencionamos en la Tabla 3. Por su parte, en la escala marina, señalaremos ciertos hitos relacionados con esquemas de conservación en Rapa Nui, principalmente respecto de las dinámicas socioinstitucionales que se generaron en torno a la creación del Parque Marino Motu Motiro Hiva (PMMMH) y el AMCP-MU.

\section{Recuperación del Parque}

Dentro de las figuras de conservación y manejo más antiguas se encuentra el Parque Nacional Rapa Nui creado en 1966 que comprende 40\% de la superficie de la isla. Desde 1972 y hasta 2015 fue administrado por la Corporación Nacional Forestal (CONAF). Ese año, la organización indígena Parlamento Rapa Nui se tomó el parque y prohibió el acceso a los sitios arqueológicos más emblemáticos de la isla. Este conflicto se remontaba a 1997, con la filmación de la película Rapa Nui, que abrió el espacio a múltiples iniciativas audiovisuales que empezaron a rodarse en la isla (Delaire, 2018). Hacia fines de 1997, un grupo de personas de la etnia estableció el cobro de un "peaje cultural" en el Parque Nacional y, en especial, en el acceso al sitio de Orongo, por el "derecho intelectual, territorial, patrimonio cultural, ancestral rapanui" (Kauffman, 1997, en Delaire, 2018, p. 161).

El trasfondo de este proceso está estrechamente ligado a la problemática de la inscripción de las tierras a nombre del fisco en 1933, la administración del fundo Vaitea y los servicios de la isla por parte de la Sociedad Administradora y de Servicios de Isla de Pascua (SASIPA) y, como desencadenante coyuntural, la mala gestión del Parque y los recursos arqueológicos por parte de la CONAF. Tal como señala Delaire (2018):
Las tierras de sus padres, amenazadas por la destrucción, visto aquí como un símbolo de la desidia chilena, tenían que volver a manos de sus dueños originales. Se cuestionaba además la controversia sobre la escasez de los fondos reservados para la isla. No resulta casual en la lógica rapanui que se pidiese cooperación a los turistas y extranjeros por los ingresos a los sitios. Esta situación se volvió a repetir en el año 2015, cuando el Parlamento rapanui decidió cerrar el acceso a los sitios sagrados para controlar el paso a estos lugares. (pp.164-165)

La antesala directa de la toma del Parque fueron las mesas de trabajo del Estatuto Especial, en las que se planteó la necesidad de recuperar el patrimonio arqueológico de la isla. La toma del Parque ocurrió en mayo de 2015 y, tras meses de negociación, el Estado propuso una consulta acerca de la coadministración del parque en conjunto con la CONAF. Esta no fue validada por la comunidad rapanui, ni por los miembros de la CODEIPA, quienes rechazaron la propuesta de coadministración y no participaron en la votación. En el marco de esta discusión, llevada por una subcomisión de la CODEIPA, y a partir de una reunión con los representantes de las familias de la isla y organizaciones como el Parlamento Rapa Nui y el Consejo de Ancianos, se creó el Honui $i^{5}$ como entidad de referencia para la coadministración del PNRN el 22 de febrero de 2016. Finalmente, el gobierno le entregó la administración del Parque a la etnia Rapanui a través de la Comunidad Indígena Mau Henua (Astudillo, 2018).

\section{Conservación y manejo en el maritorio}

Las primeras áreas de conservación marina en Rapa Nui fueron establecidas por la Subsecretaría de Marina (Ministerio de Defensa) en 
1999, con el establecimiento de los Parques Submarinos Coral Nui Nui, Motu Tautara y Hanga Oteo. Estas iniciativas, creadas bajo un enfoque de manejo "desde arriba", no contaron con consulta pública previa ni con la participación de la comunidad (Paredes, Flores, Figueroa, Gaymer \& Aburto, 2019). Posteriormente, en 2004, una Subcomisión de Borde Costero de la CODEIPA planteó generar un área de reserva en la zona de la caleta de pescadores Hanga Roa o Tai. Esta iniciativa fue encabezada por la Cámara de Turismo de la Isla, personas vinculadas a la actividad marina-pesquera y, a nivel administrativo local, el Municipio y la Gobernación, y nacional, la SUBPESCA y el Ministerio de Economía y Finanzas. Sin embargo, dado que los pescadores rechazaron la idea de áreas de "reserva" o "parque" y por la falta de consenso con la SUBPESCA, la iniciativa fue desestimada hacia 2012.

La creación del Parque Motu Motiro Hiva, en 2010, es un hito importante en las relaciones con el Estado chileno y con grandes ONG que fueron parte de este proceso. Las ONG internacionales OCEANA y National Geographic Society, junto a investigadores nacionales, realizaron una expedición científica exploratoria a las islas oceánicas de Sala y Gómez, conocidas en la tradición rapanui como Motu Motiro Hiva, con el fin de dar cuenta de su importancia biológica. A partir de esto, realizaron gestiones a nivel gubernamental, lo que permitió que en el marco de la iniciativa denominada "Legado Bicentenario", el Ejecutivo tomara el nombre de tradición rapanui, y decretara la creación del parque marino Motu Motiro Hiva, que abarca las islas Sala y Gómez y 150.000 km² a la redonda. Posteriormente, estas ONG organizaron una segunda expedición, que incluyó las aguas en torno a Rapa Nui, para la recopilación de datos cuantitativos, la cual generó, como recomendación en su informe científico, la expansión del parque marino en torno a Rapa Nui a través de una reserva marina en Hanga Roa (OCEANA, 2011). Respecto de este proceso, nuestros entrevistados nos señalaron lo siguiente:

\begin{abstract}
Motu Motiro Hiva y lo tomaron, sin consulta a la gente de la isla. Porque se supone que eso tiene que haber una consulta previa y después tomarlo como un parque, porque Motu Motiro Hiva no es ajeno a la isla. Porque para mí Motu Motiro Hiva está aquí mismo, porque imagínate en estos tiempos yo iba a pescar allá en una lancha, pero a mí me contó mi abuelo que sus ancestros iban a pescar allá en botes de madera o de totora iban a pescar, a remo, a vela. Iban a charquear el pescado allá y calcular el viento y la corriente, se volvía de vuelta, entonces era algo nuestro. ¿Cómo puede ser un gobierno que llega en un día para otro y lo nombra como parque reserva sin consulta de nosotros?. (N. S., marzo 2019)
\end{abstract}

Paralelamente, otra ONG internacional, PEW Charitable Trust, presentó a la CODEIPA una propuesta de parque marino para Rapa Nui. Se generó entonces una pugna entre estas ONG por el liderazgo frente a una futura área no take ${ }^{6}$, que concluyó en la prevalencia de PEW en la isla a través de mecanismos de alianzas con el Municipio y apoyo financiero a individuos y organizaciones (Aburto, Gaymer \& Govan, 2020), lo que produjo una división en la comunidad (Aburto, Gaymer \& Cundill, 2017) y fuertes desconfianzas que se mantienen hasta hoy.

Estos eventos generaron una movilización dentro de la comunidad, que observaba este proceso como nuevas formas de colonialismo. Sobre esto, un entrevistado, vinculado a la Mesa del Mar, nos señaló: “¿Cómo se hizo el parque Motu Motiro Hiva? Se hizo muy mal, es ese que gatilla ese interés hacia el mar y la toma de decisiones” (M. U., marzo 2019). 
Sumado a esto, la presencia del mundo académico en la isla (Aburto et al., 2015) promovió que organizaciones e instituciones en Rapa Nui llevaran a cabo un "Cabildo del Mar", con el objetivo de generar propuestas desde la comunidad para el mar rapanui. Estas pusieron el énfasis en la gestión local del mar mediante la creación de un Consejo del Mar y mecanismos de protección basados en las formas tradicionales de pesca:

[...] uno de los resultados [del Cabildo del Mar] fue constituir un ente público-privado que fuera como encargado de la administración del mar y la previsión de la parte de legal, y decretar un área de protección, etc. Entonces de ahí PEW se empezó a agarrar para decir que había un Cabildo del Mar y que el pueblo de Rapa Nui había pedido la creación de un Parque Marino, después de eso constituyeron la Mesa del Mar. (D. M., febrero 2019)

Las organizaciones locales que participaron en el desarrollo del cabildo conformaron la Mesa del Mar Te Mau o Te Vai Kava. Sin embargo, debido a la injerencia cada vez mayor de PEW dentro de dicho espacio, algunas organizaciones fundantes se retiraron, como TAPU, y algunas asociaciones de pescadores. Al respecto nos comentaron:

Participamos mucho tiempo, fuimos fundadores de la Mesa del Mar, pero ahí también se da cuenta del tema de los recursos y a veces quien financia pone su visión por sobre el espíritu de lo que uno está haciendo y ahí finalmente me retiré de la mesa del mar. (Q. I., febrero 2019)

Durante 2015 se intensificó la campaña de la Mesa del Mar en pro de un parque marino no take para Rapa Nui. Esto es señalado como una estrategia de un fuerte lobby de PEW ante esferas políticas del gobierno:
PEW empieza, vuelve a nivel ministerial, de medio ambiente [...] se saltan a todo el mundo por todos lados, la Mesa del Mar. Y PEW, en la época de la Bachelet, tenía... un operador de PEW dentro de la SUBPESCA (D. M., febrero 2019).

La movilización de influencias a niveles gubernamentales tuvo su momento cúlmine con la conferencia "Our Ocean". En este evento, la Mesa del Mar, apoyada por el municipio y PEW, impulsó un anuncio que venía del Ejecutivo, la creación de un parque marino para Rapanui. Ante esto, la CODEIPA respondió denunciando que se buscaba un acuerdo a espaldas de dicho organismo ${ }^{7}$. Sobre este momento nos señalaron:

La CODEIPA sacó una declaración diciendo que el parque marino no correspondía, porque el parque marino en el fondo era una figura de protección escondida, que le quitaba los derechos de los recursos naturales a los pueblos, que era una forma de sustentabilidad. (D. M., febrero 2019)

Frente a esto, la CODEIPA, por medio de la Gobernación de la isla, realizó reuniones con el gabinete de la presidenta Michelle Bachelet. Tras estas conversaciones, este anunció el compromiso del gobierno por crear un área de protección marina y no un parque. Sin embargo, estos sucesos acrecentaron la brecha entre quienes trabajaban y apoyaban la Mesa del Mar y la creación de un parque marino y quienes la rechazaban asociándola a una intervención de PEW en la isla a través de esa instancia. Tal como señala Rafael Tukï:

[...] la solicitud de parque marino no nace de la iniciativa del pueblo rapanui, sino que es una propuesta envasada desde una ONG extranjera. Se ha simulado la representación del pueblo rapanui en la denominada Mesa del Mar, y los denominados "cabildos", financiados por la ONG, pero todo está pauteado. Nosotros 
queremos proteger el mar, evitar la pesca ilegal y la depredación, pero con respeto a la autonomía y en beneficio de los derechos del pueblo rapanui, y no de una ONG transnacional extranjera. (R. Tuki, 2015)

Como se señaló anteriormente, en 2016, la CODEIPA buscaba incluir el tema marino y del PNRN en el marco del Estatuto Especial. Al mismo tiempo, la Mesa del Mar presionaba para la realización de la consulta en torno al parque marino. Un integrante de esta nos explicó:

De ahí el gobierno tira el elástico [...] se extendió el chicle [...] para la CODEIPA, nuestra autoridad local en este momento, el mar no era prioridad, para ellos la prioridad era el tema del Parque y... la Ley de Residencia. Pero nosotros hinchamos, porque hoy día se creó el área marina protegida y todos lo hicimos, sí, es un trabajo en conjunto, pero si no hubiera existido que Te Mau o Te Vaikava hinchado para que se haga la consulta, no se hace la consulta, así de simple. (M. U., marzo 2019)

Al no concretarse el Estatuto Especial, la CODEIPA buscó los acuerdos necesarios para generar un esquema de protección marina con la soberanía del pueblo rapanui:
Le dijimos a Relaciones Exteriores (Ministerio) que o nos daban un parque con nosotros adentro y ellos dijeron que no, que lo que podían hacer es un área marina de múltiples usos. Nosotros le dijimos vale, un área marina múltiples usos para el territorio especial de Isla de Pascua con uso exclusivo de los rapanui, si no no puede ser, porque no hay sentido. No quiere decir que solo yo como rapanui lo voy a usar, pero voy poder tener autoridad de decir, oye sacas cinco pescados no te lleves cien. (B. N., marzo 2019)

En estas negociaciones se acordó la consulta sobre el AMCP-MU para el año 2017. Para ello se formó un Comité Técnico Interministerial ${ }^{9}$, que se articuló, además, con el Consejo de Ancianos, Honui, asociaciones de pescadores y la Mesa del Mar para informar y organizar la consulta con las 36 familias y demás organizaciones de la isla. Con la consulta se determinó la cantidad de integrantes del consejo pertenecientes al pueblo rapanui, la incorporación del parque marino en el plan de administración del AMCP-MU y las prohibiciones de pesca industrial, entre otros (MMA, 2017) puntos que fueron incorporados en las preguntas de la consulta (Figura 1), luego de instancias de diálogo con el Estado (Aburto et al., 2020). 
Figura 1: Las preguntas, en rapanui y español, que contenía el voto de la consulta del mar.

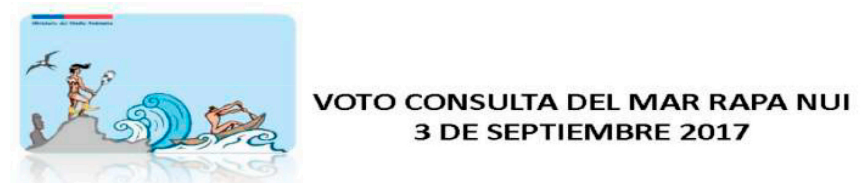

\begin{abstract}
1.- ¿E tano rō 'à ki a koe mo ana i te Área Marina Costera Protegida de Múltiples Usos o Rapa Nui, haka ré 'e kì te mau o roto mo te rapa nui mau nō 'e te ana 'e te haka tere ananake ko te Estado?

¿Está de acuerdo con la creación del Área Marina Costera Protegida de Múltiples Usos Rapa Nui, que reconozca y garantice los recursos al pueblo Rapa Nui y la administración y gestión con el Estado?

'E-ēe-Si $\square$
\end{abstract}

2.- ¿E tano rō 'à ki a koe te ana 'e te haka tere i te MCPMU ananake ko te Estado e haka tu'u e tahi nūna'a 'i roto e 6 rapa nui 'e e 5 o te Estado?

¿Está de acuerdo que la administración y gestión conjunta con el Estado, se realice en un consejo directivo compuesto por 6 representantes del Pueblo Rapa Nui y 5 del Estado?

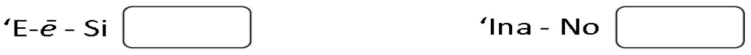

3.- E tano rō 'à ki a koe ana hì hai huru 'e hai rāve'a mau nō o te haka tere ina o te nu'u tere vaikava o Rapa Nui?

¿Está de acuerdo que la pesca se realice únicamente con artes y aparejos de pesca artesanales del pueblo Rapa Nui?

\begin{tabular}{l|l} 
'E-e- $-\mathrm{Si}$ & 'Ina-No \\
\hline$N^{\circ}$ &
\end{tabular}

Fuente: Ministerio de Medio Ambiente, 2017, p. 6.

La Consulta del Mar se realizó en septiembre de 2017, 417 personas (de 612) votaron por la opción "Sí". El AMCP-MU fue promulgada en junio de 2018 (Figura 2) y en septiembre se realizó la elección de los representantes rapanui en el Consejo del Mar. Se presentaron 31 candidatos, 1.133 personas eligieron a los seis representantes que obtuvieron el mayor número de votos: Felipe Nahoe (pescador artesanal), Juan Tuki (pescador), Mike Rapu (buzo-empresario turístico-ex participante de la Mesa del Mar), Anastasia Teao (presidenta asociación de pescadores), Melitón Tuki (pescador artesanal-Honui) y Petero Avaka (pescador artesanal-participante de la Mesa del Mar). Cabe destacar, si bien muchos de los candidatos eran jóvenes que participaron y organizaron el cabildo, la Mesa del Mar y otras iniciativas, los representantes elegidos fueron miembros de mayor edad y por su oficio vinculado al mar; algunos de ellos habían sido fuertes opositores a la iniciativa de un parque marino. 
Figura 2. a) Superficie que comprende el área de protección del Rapa Nui, que incluye el AMCP-MU y PMMH. b) La superficie de las áreas en relación con la distancia con Chile continental y el área del Parque Marino de Juan Fernández

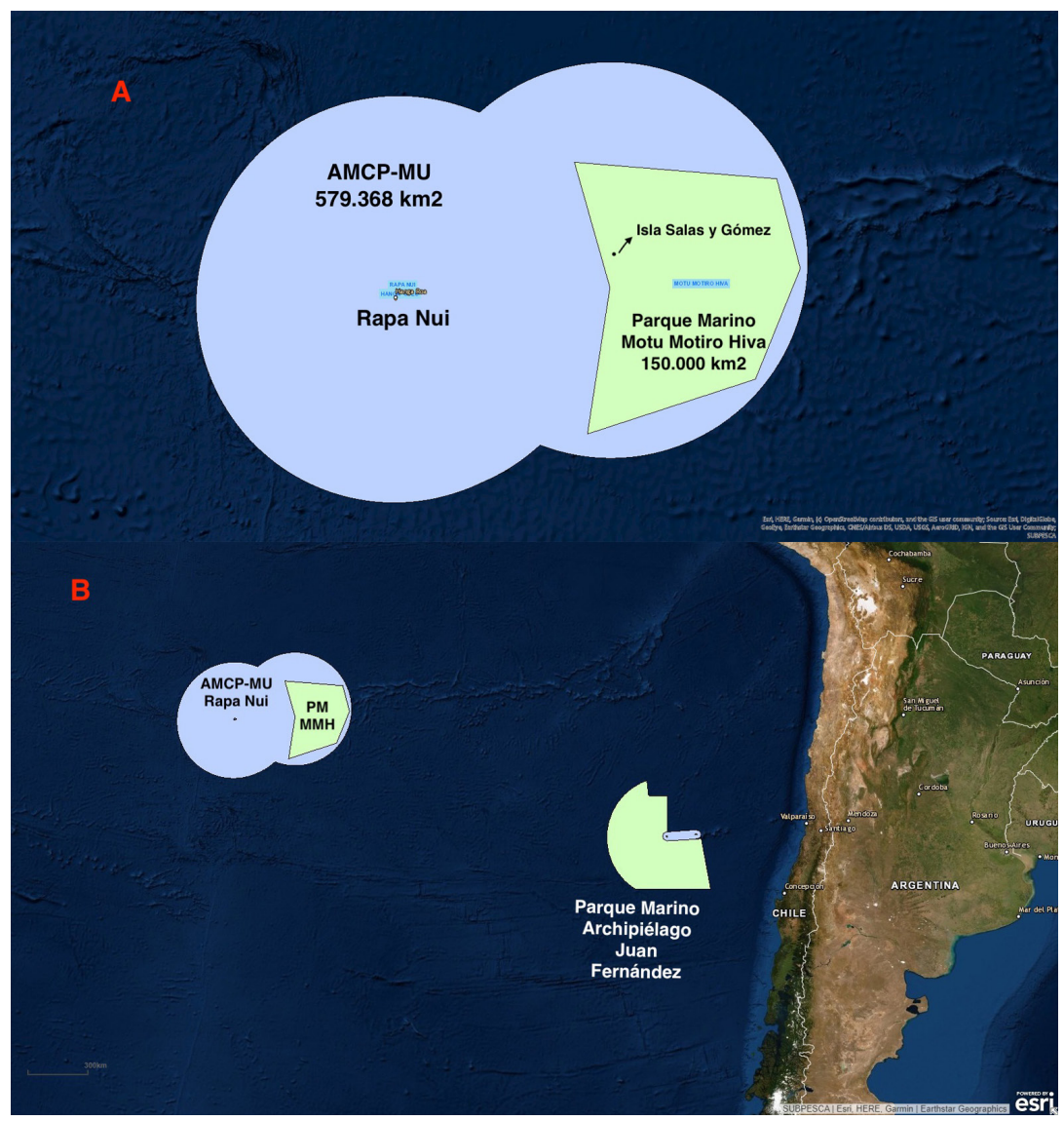

Elaboración propia con base en el visualizador de mapas SUBPESCA, https://mapas.subpesca.cl/ideviewer/

El Consejo Directivo del AMCP-MU fue presentado oficialmente en agosto, durante la visita del presidente Sebastián Piñera a la isla. Este quedó conformado por los seis representantes rapanui electos y cinco representantes del Estado chileno: Ministerio del Medio Ambiente (secretaría técnica), Ministerio de Defensa Nacional, Ministerio del Interior y Seguridad Pública, representado por la Gober- nación Provincial de Isla de Pascua, SERNAPESCA (dependiente del Ministerio de Economía, Fomento y Turismo) y un comisionado electo de la Comisión de Desarrollo de la Isla de Pascua (CODEIPA). Son, por tanto, ocho representantes rapanui y tres continentales.

A partir de octubre de 2018, el Consejo Directivo se reunió trimestralmente y eligió a 
la gobernadora de Rapa Nui, Tarita Alarcón Rapu, como presidenta de dicho Consejo. Por su parte, el Consejo del Mar comenzó a generar una dinámica de trabajo sistemática con reuniones semanales o quincenales junto con otros miembros del Consejo Directivo, como la Gobernación Provincial y el representante de la CODEIPA. Desde 2019, el Consejo del Mar comenzó a trabajar con una secretaría técnica y asesoría técnica por parte de integrantes de la Mesa del Mar. El trabajo del Consejo Directivo se ha centrado principalmente en la redacción del reglamento de funcionamiento. Las acciones referentes al plan de administración del AMCP-MU y el Parque Marino están siendo elaboradas por investigadores de la Universidad Católica del Norte para ser presentadas a la comunidad durante 2020.

\section{Conservación como un camino de autonomía}

Hemos tratado de mostrar cómo las iniciativas de conservación se enmarcan en los procesos etnopolíticos de la isla. Desde los años noventa, la institucionalidad chilena comienza con mayor fuerza a hacerse presente en la isla. Al mismo tiempo que el pueblo rapanui va generando y construyendo nuevos espacios de acción, apropiándose de espacios políticos-administrativos, como el municipio y la gobernación, se genera una rapanuización de las instituciones públicas, las normas y los mecanismos de funcionamiento (McCall, 1996; Andueza, 2000). Un representante de CODEIPA lo señala de la siguiente manera:

En cierto modo todo eso se va logrando por esa demanda [de autonomía]. La isla, en cierto modo, por un lado, avanzó con estas cosas, con que el Estado te pasara la cesión del Parque, la Ley de Residencia y que pudieras lograr la administración del mar. Por otro carril, hay una demanda internacional por lo de la autonomía que nos merecemos. Estos caminos, en un momento, se deben de juntar. Por el lado del Estado se ha logrado algo, estamos ejerciendo el derecho, ejercerlo, no lo tenemos en papel. Pero de poco a poco algo hemos logrado. (A. N., marzo 2019)

Esto lo entendemos como parte de una estrategia etnopolítica frente al colonialismo "institucionalizado" por parte del Estado chileno (Delsing, 2017). Pese a esta rapanuización, el gobierno de Chile ha enfocado sus esfuerzos, en la última década, principalmente en problemas derivados de la insularidad ${ }^{10}$ (aislamiento, transporte y desarrollo productivo, migración), aunque no ha logrado resolver estas problemáticas, incluso se han acrecentado. Mientras tanto, la demanda de autonomía por el control territorial de Rapa Nui persiste (Lagos \& Escobar, 2009). Esta es percibida como el camino legítimo para enfrentar, en la escala local, las ausencias del Estado, lo cual se hace patente en la gestión del mar. Por ejemplo, las políticas pesqueras aplicadas en la isla han apostado a la regulación de las prácticas usadas en el continente, como el registro de pesca artesanal (Aburto et al., 2015), sin considerar las reivindicaciones locales de usos de los recursos marinos.

Un delegado del Consejo del Mar señaló: "la autonomía que queremos es manejo de nuestras áreas, de nuestras cosas, tenemos ese derecho, es ancestral" (N. S., marzo 2019). Esta idea está relacionada con uno de los elementos basales de la cultura rapanui, aquel referido al culto a los ancestros. La idea de ancestralidad de las demandas de autodeterminación alude a ese vínculo indivisible en el rapanui entre el pasado y el futuro. El legado 
de los ancestros es, por tanto, la tierra, kainga, que conjuga el territorio y el maritorio y la propia historia de lucha y reconocimiento étnico (Lagos \& Escobar, 2009).

El área marina protegida, entonces, se concibe como un logro: "Se estuvo luchando por la autonomía y se logró autonomía para 700.000 km²". En este sentido, el AMCP-MU es vista como una forma de soberanía territorial frente a la fuerte injerencia de ONG internacionales que, con su propuesta de parque marino, iban en detrimento del uso actual y futuro de los recursos marinos del pueblo rapanui. El proceso que llevó a la declaración del área protegida puso de manifiesto la fuerza de la comunidad, sus organizaciones e instituciones de representación de la etnia. Gracias a ello se logró el objetivo de una protección del mar que contemplara los usos tradicionales-artesanales, mediante la cual se logra, por defecto, una prohibición de la pesca industrial (como no se ha logrado en Chile continental) y tener una representación mayoritaria de la etnia en el consejo de administración.

Respecto a la representación de la etnia, el trabajo de la CODEIPA permitió que el proceso de creación del área saliera de la presión ejercida por la ONG PEW, al recuperar el liderazgo y enmarcarlo en los procesos de reivindicación a escala territorial a través del Estatuto Especial de Administración. La experiencia de la CODEIPA en las negociaciones con el Estado y en los mecanismos de acción gubernamental ayudó a encontrar un camino más cercano a la demanda local respecto de la gestión marina al conseguir la mayoría en el Consejo Directivo y un voto vinculante. Por otro lado, el hecho de que los consejeros rapanui fueran designados por votación y no elegidos por un mecanismo de delegados de organizaciones sociales, como sucede en muchos espacios de gobernanza de áreas protegidas, dota de legitimidad la representación. En este caso, los consejeros electos responden a diversos clanes y tipos de organizaciones. En efecto, algunos de los representantes también son miembros del Honui, por lo que, a través suyo, se traspasa a la organización social de base que tiene la etnia hoy el abordaje de los diferentes temas que la convocan.

Otro elemento importante en el proceso de implementación de las áreas de protección marina es el relativo a la escala relacional y de acción de los actores como agentes en su desarrollo (Alexander \& Armitage, 2015). En Rapa Nui, tal como señalan Aburto \& Gaymer (2018), fue una organización de jóvenes interesados en la conservación la que canalizó las primeras acciones que permitieron llevar adelante el Cabildo del Mar y la conformación de la Mesa del Mar, instancias clave para la creación del área. En ese sentido, Paredes et al. (2019) destacan lo importante que fueron los procesos de construcción de conocimientos entre la academia y los rapanui como base para la generación de capacidades a nivel local, lo que potenció el proceso de creación del área desde una democratización del conocimiento de los ecosistemas y la valorización del conocimiento ecológico local.

Por otro lado, la entrada de PEW en la isla generó tal nivel de conflicto social que terminó por ser percibida como impulsora de mecanismos de cooptación en su despliegue en la isla. Sin embargo, para algunos miembros de la Mesa del Mar, se utilizó el apoyo de PEW para lograr los objetivos de conservación propios. 


\section{Discusión}

Hemos planteado una serie de hitos en los procesos etnopolíticos de Rapa Nui que, de manera separada, articulan, según el contexto particular de cada coyuntura, formas de relación con el Estado u otros agentes de dominación. En una mirada diacrónica-sincrónica, el proceso en su conjunto nos habla de la búsqueda y la puesta en marcha de mecanismos de superación del dominio colonial sobre el pueblo rapanui. Finalmente, como parte de las trayectorias etnopolíticas de este pueblo, hay que entender la emergencia del AMCP-MU sumándola a cada uno de los hitos que recorrimos, es decir, de manera agregada. Ese palimpsesto ${ }^{11}$ histórico y territorial es el que le ha permitido al pueblo rapanui poder enfrentar al Estado y ejercer su soberanía política (Mawyer \& Jacka, 2018) para recuperar tanto su patrimonio arqueológico como la gestión de su biodiversidad y de su maritorio.

Tal como señala Delsing (2017), a través de sus propios dispositivos culturales de reapropiación de las estructuras coloniales, los rapanui han abierto caminos de posicionamiento de su cultura, su cosmovisión y su propia historia. En esta línea, la tradición y la cultura ancestral no son estructuras estáticas, sino que se revitalizan y funden en la construcción de las estrategias etnopolíticas por la autodeterminación. Ejemplo de esto es la relectura de la figura de los jefes de los clanes en las instituciones, tal como el Consejo de Ancianos o Honui (Delsing 2017), o bien la CODEIPA, como una figura emergente y aglutinante para la administración de los recursos arqueológicos y ambientales de la isla.

Al mismo tiempo, estos elementos forman parte de una cultura de resistencia (Bartolomé,
2002) en Rapa Nui. El respeto por las investiduras de los jefes a que hace alusión el Acuerdo de Voluntades se traduce hoy en la autoridad que emana del pueblo para la gestión del territorio. Por otro lado, este último, el territorio ancestral, es un eje de la demanda política. Esta idea de territorio ancestral reúne toda la significación en torno a la noción de kainga (Delsing, 2017), así como el pasado, el presente y el futuro, las conexiones con las culturas polinésicas y el mar como fuente de dicha historia. En la medida que el territorio se conjuga por y en el tiempo (Ther-Ríos, 2012), encerrando la memoria histórica (Bartolomé, 1997), los diferentes hitos de la historia rapanui, desde el Acuerdo de Voluntades hasta las actuales iniciativas de conservación, configuran la base de la demanda ancestral de autonomía sobre el territorio y sus recursos naturales.

La sociedad rapanui, como otros pueblos originarios, aparece para el Estado nacional, en este caso para el chileno, históricamente, como una colectividad con poca validación en las acciones que toma en pos de su devenir como pueblo, lo que la sitúa en un doble aislamiento, no solo geográfico, sino también discursivo. Es por esto que la autonomía aparece como un elemento clave para la superación de este y para la validez de las demandas. Sin embargo, ese doble aislamiento histórico que vive la isla es resignificado y redimensionalizado para, como plantea Bartolomé (2002), poder negociar hoy con el Estado, desde sus propias estructuras políticas, tales como la CODEIPA, las formas de articular la autodeterminación territorial.

En este contexto, el mar es un objeto político, como plantean Mazé et al. (2017) y, por tanto, las iniciativas de conservación marina, como las AMP, pueden ser consideradas como una 
acción etnopolítica utilizada como una herramienta institucional para el reconocimiento legal de la propiedad indígena y la recuperación del control colectivo del mar (Araos et al., 2020b). Tal como señalan estos autores para el caso de los espacios costeros marinos de pueblos originarios en el sur de Chile, se busca, entre las diferentes opciones de la institucionalidad chilena, un esquema que cumpla con los objetivos de la comunidad rapanui para ir avanzando, desde autonomías administrativas, con esquemas de cogestión como el AMCP-MU o el PNRN, a una autonomía territorial plena. En este sentido, el AMCP-MU de Rapa Nui genera un espacio de coadministración con el Estado que, a través del Consejo del Mar, busca que la gestión se determine localmente, lo que apunta a una autonomía de facto.

La discusión en torno a la conservación y las AMP pone en el centro la cuestión de quién toma la decisión (West et al., 2006). Esta determinante es fundamental si nos situamos en los procesos más globales vinculados al mar, en los que las áreas marinas protegidas constituyen un factor que no es inocuo. Las iniciativas de conservación se desarrollan a nivel mundial y en cada país son enmarcadas como una respuesta a los acuerdos internacionales (De Santo, 2013). Por ello las AMP en nuestro país deben ser pensadas desde el rol que cumplen en el contexto geopolítico del Pacífico sur, en el marco de las llamadas economías azules.

La aplicación de estos esquemas implica, por un lado, el desarrollo de esquemas de gobernanza en países como Chile con escasos espacios de participación real en la gestión territorial y que han llevado adelante, como señalan Aburto et al. (2020), procesos de acaparamiento del océano como el que se desarrolló en torno al parque marino $\mathrm{MMH}$. Pese a esto, este proceso logró ser revertido a través de la movilización política rapanui, con lo que se cimentaron no solo los futuros procesos en torno a la conservación marina, sino los de la gestión de todo el territorio de manera soberana.

\section{Conclusiones}

En este trabajo hemos querido vincular dos elementos que tradicionalmente han sido analizados de manera separada: los procesos de conservación y gestión de recursos y aquellos de reivindicación territorial y étnica. Esto, principalmente, ha sido por la lenta incorporación de las ciencias sociales en el área de las ciencias de la conservación y la sustentabilidad y la falta de paridad y reconocimiento del conocimiento social frente al de las ciencias naturales, y más aún en el plano de las políticas públicas ambientales (Bennet et al., 2017). Sin embargo, en la medida que la gestión de recursos naturales es una actividad inherente humana, no es posible analizar el manejo y la conservación de los ecosistemas sin entenderlos en el contexto de trayectorias sociopolíticas que ocurren en la escala local.

En este sentido, entendemos las iniciativas de creación de áreas marinas protegidas en Rapa Nui como parte de un proceso de apropiación y restitución de derechos sobre su maritorio, el que se enmarca en una estrategia de avanzar por diferentes caminos en la recuperación de la autodeterminación del futuro de su propia tierra, como es el control migratorio y la recuperación de su patrimonio arqueológico. Esto se articula con los diferentes "hitos" que a lo largo de la historia dan cuenta de las demandas etnopolíticas del pueblo rapanui, desde la Anexión, 
con la que los jefes de los clanes buscan el reconocimiento del poder que los investía; el movimiento de Anata contra la explotación colonial; el movimiento anticolonialista de Alfonso Rapu y la búsqueda de reconocimiento étnico y derechos ciudadanos; la visibilización de su historia y demandas ante la Comisión de Verdad y Nuevo Trato y, por último, la búsqueda de un Estatuto Especial de Administración que pueda cristalizar su demanda de autonomía. Lo que aquí vemos como elemento conductor es la capacidad de adaptación política y de negociación con las estructuras dominantes con las que la isla ha debido relacionarse a lo largo de su historia (Lagos \& Escobar, 2009).

La conservación de los ecosistemas costeros-marinos es un imperativo, sobre todo en una sociedad de origen polinésico como la rapanui, donde la base de la reproducción social es la conexión con el mar, por lo que conservar el mar y sus especies es conservar la cultura y la propia vida de cada rapanui. Sin embargo, el desarrollo de las áreas protegidas, desde una mirada tecnocrática occidental que separa la vida natural y cultural en pos de supuestos estándares de sustentabilidad, apunta tradicionalmente a un desacople de la vida sociopolítica de los pueblos que son, en teoría, beneficiarios de dichos esquemas. En este sentido, pudimos ver que el proceso que llevó a la creación del área marina de Rapa Nui tiene un trasfondo etnopolítico más profundo que la mera conservación. De alguna manera, para muchos pueblos como el rapanui, este tipo de esquemas de protección ambiental, tales como áreas protegidas o de manejo, son resignificados desde lo local como hitos de recuperación territorial para la autodeterminación de su propio futuro.

\section{Agradecimientos}

Nuestro profundo agradecimiento a todas las personas del pueblo rapanui y chilenos residentes en la isla, miembros de instituciones, organizaciones o personas particulares que colaboraron con el desarrollo de este trabajo a través de sus testimonios y el apoyo desinteresado. A Astrid Mandel, por sus sugerencias para mejorar este trabajo. Agradecemos el financiamiento para la realización del trabajo de campo de los Fondos para Núcleos Temáticos de Investigación 2005 y 2006 de la Universidad Academia de Humanismo Cristiano otorgados a A. S. De igual manera, el trabajo de campo durante 2019 fue posible gracias a la Beca de Apoyo a Docentes en Estudios de Doctorado de la Comisión Académica de Posgrado de la Universidad de la República del Uruguay otorgado a X. L. A Macarena Barahona por su gran apoyo a X. L. en el trabajo de campo en Rapa Nui en 2019 y a partir de ahí a la distancia. Agradecemos los comentarios constructivos de los evaluadores anónimos que permitieron mejorar el manuscrito original. 


\section{Notas}

${ }^{1}$ El culto a los ancestros es un elemento clave para la cultura rapanui, pasada y presente. Las estructuras poscoloniales, en especial, socavaron la orgánica política y simbólica rapanui al apropiarse del territorio e instalar prohibiciones y obligaciones de diversa índole, frente a lo que la comunidad ha respondido, a lo largo de su historia, apelando a su herencia política y simbólica, elementos que en la cosmovisión polinésica no están separados. De igual manera, el territorio y el maritorio son elementos esenciales en la construcción de su identidad. Por ello hablamos de una demanda ancestral y no meramente histórica.

${ }^{2}$ Comerciante chileno-francés que formó en 1897 la Compañía E. Merlet, la cual se estableció en los antiguos terrenos de la Compañía Brander.

${ }^{3}$ El Relator Especial visitó Chile en julio de 2003. En este tiempo sostuvo reuniones con miembros de la Comisión de Verdad Histórica y Nuevo Trato que se encontraban en la etapa final de la elaboración del informe.

${ }^{4}$ Comisión de Derechos Humanos, 60ํํํodo de sesiones (2004), Informe del Relator Especial sobre la situación de los derechos humanos y las libertades fundamentales de los indígenas sobre su visita a Chile.

${ }^{5}$ En el proceso por la administración del PNRP, cada una de las 36 familias rapanui eligió un representante Honui para participar en dichas reuniones, llevar la información a las familias y la posición de estas en las diferentes citas. Honui, viene de la noción de tangata Honui, que refiere a un sabio, por lo que identifica a quien lleva la voz, el vocero o representante. Se planteó inicialmente como una alternativa para la administración del PNRN, que finalmente recayó en la Comunidad Indígena Ma'u Henua, pero respecto a la cual el

\section{Referencias bibliográficas}

Aburto, J. A. \& Gaymer, C. F. (2018). Struggling with socialecological mismatches in marine management and conservation at Easter Island. Marine Policy, 92, 21-29. doi: https://doi.org/10.1016/j. marpol.2018. 01.012

Aburto, J. A., Gaymer, C. F. \& Cundill, G. (2017). Towards local governance of marine resources and ecosystems on Easter Island. Aquatic Conservation: Marine and Freshwater Ecosystems, 27, 353-371. doi: https://doi.org/10.1002/aqc.2665

Aburto, J. A., Gaymer, C. F. \& Govand, G. (2020). A large scale marine protected area for the sea of Rapa Nui: From ocean grabbing to legitimacy? Ocean \& Coastal Management, 198,2020,105327. doi: https://doi.org/10.1016/j.ocecoaman.2020.105327

Aburto, J. A., Gaymer, C. F., Haoa, S. \& González, L. (2015). Management of marine resources through a local governance
Honui actúa como entidad fiscalizadora (Astudillo, 2018).

${ }^{6}$ Del inglés "no take areas". Refiere a áreas marinas protegidas que no admiten capturas de especies.

${ }^{7}$ Representantes rapanui se oponen a constitución de inconsulto Parque Marino que los privará de la utilización de sus recursos, Prensa Rapanui, 6 de octubre de 2015. Recuperado de http://prensarapanui. blogspot.com/2015/10/representantes-rapa-nui-se-oponen.html.

${ }^{8}$ Dirigente rapanui afirma que ONG PEW dio incentivos monetarios a isleños para que aprobaran el Parque Marino, El Desconcierto, 3 de octubre de 2015, recuperado de https://www.eldesconcierto. cl/2015/10/03/dirigente-rapanui-afirma-que-ong-pew-dio-incentivosmonetarios-a-islenos-para-que-aprobaran-el-parque-marino/.

${ }^{9}$ Fueron parte del Comité: División de Recursos Naturales y Biodiversidad (Ministerio de Medio Ambiente); representantes del Ministerio de Relaciones Exteriores y de la Subsecretaría de Pesca (Ministerio de Economía y Finanzas); la Dirección General del Territorio Marítimo, y la Marina Mercante de Chile (Armada de Chile) y Fuerzas Armadas (MMA, 2017)

${ }^{10} \mathrm{El}$ abastecimiento es una problemática latente. Con frecuencia hay problemas con los barcos y las empresas de carga que transportan a la isla, situación que se ve agudizada por el monopolio de la línea área LATAM con los vuelos a la isla, lo que ha establecido costos muy elevados. Estos elementos han sido un fuerte argumento por el cual el alcalde de Rapa Nui, Petero Edmunds, defiende la necesidad de autonomía para la isla, más aún en el contexto de la crisis sanitaria provocada por la pandemia de COVID-19.

${ }^{11}$ Palimpsesto, cuya raíz griega, significa "grabado nuevamente", refiere a un manuscrito antiguo que conserva huellas de una escritura anterior borrada artificialmente. perspective: Reimplementation of traditions for marine resource recovery on Easter Island. Ocean and Coastal Management, 116, 108-115. doi: https://doi.org/10.1016/j.ocecoaman.2015.07.008

Araos, F., Catalán, E., Álvarez, R., Núñez, D. J., Brañas, F. \& Riquelme, W. (2020a). Espacios costeros marinos para pueblos originarios: Usos consuetudinarios y conservación marina. Anuário Antropológico [Online], I. Recuperado de http://journals.openedition. org/aa/4933. doi: https://doi.org/10.4000/aa.4933.

Araos, F., Anbleyth-Evans, J., Riquelme, W., Hidalgo, C., Brañas, F., Catalán, E., Núñez, D. \& Diestre, F. (2020b). Marine indigenous areas: Conservation assemblages for sustainability in Southern Chile, Coastal Management, 48(4), 289-307. doi: https:// doi.org/10.1080/08920753.2020.1773212.

Alexander, S. \& Armitage, D. (2015. A social relational network 
perspective for MPA science. Conservation Letters, 8(1), 1-13.

Álvarez, R., Ther-Ríos, F., Skewes, J., Hidalgo, C., Carabias, D. \& García, C. (2019). Reflexiones sobre el concepto de maritorio y su relevancia para los estudios de Chiloé contemporáneo. Revista Austral de Ciencias Sociales, (36), 115-126. doi: https://doi.org/10.4206/rev. austral.cienc.soc.2019.n36-06

Andueza, P. (2000). Hacia el reconocimiento de los derechos políticos de los pueblos originarios. Estudios Atacameños, (19), 113-120.

Astudillo, A. (2018). Rapa Nui, un camino a la Autonomía. Rapa Nui, Santiago: Rapanui Press.

Bartolomé, M. A. (1997). Gente de costumbre y gente de razón. México: Siglo XXI.

(2002). Movimientos indios en América Latina: Los nuevos procesos de construcción nacionalitaria. Desacatos, (10), 148-166.

Begossi, A., (2010). Small-scale fisheries in Latin America: Management models and challenges. MAST, 9(2), 7-31.

Bennett, N.J. \& Dearden, P. (2014). Why local people do not support conservation: Community perceptions of marine protected area livelihood impacts, governance and management in Thailand. Marine Policy, 44, 107-116.

Bennett, N. J., Govan, H. \& Satterfield, T. (2015). Ocean grabbing. Marine Policy, 57, 61-68.

Bennett, N. J., Roth, R., Klain, S. C., Chan, K. M, Clark, D. A., Cullman, G., et al. (2017). Mainstreaming the social sciences in conservation. Conservation Biology, 31(1), 56-66.

Castro, N. (2007). El diablo, Dios y la profetisa: Evangelización y milenarismo en Rapa Nui. 1864-1914. Rapanui: Rapa Nui Press.

D’Arcy, P. (2006). Significant spaces: The role of marine ecosystems in Pacific Island cultures. Transforming Cultures eJournal, 1(2), 34-43.

De Santo, E. M. (2013). Missing marine protected area (MPA) targets: How the push for quantity over quality undermines sustainability and social justice. Journal of Environmental Management, 124, 137146. doi: https://doi.org/10.1016/j.jenvman.2013.01.033.

Delaire, N. (2018). El Parlamento rapanui 2001-2015. (Tesis inédita de doctorado). Universidad de Chile, Santiago.

Delsing, R. (2017). Articulando Rapa Nui: Políticas culturales polinésicas frente al Estado chileno. Santiago: LOM.

Díaz-Polanco, H. (1999). Autonomía regional: La autodeterminación de los pueblos indios. México: Siglo XXI.

Fuentes, M. (Ed.) (2013). Rapa Nui y la Compañía Explotadora 1895-1953. Rapa Nui: Rapa Nui Press.

Grifferos, A. (1995). La otra cara del paraíso: Comunidad, tradición y colonialismo en Rapanui 1864-1964. (Tesis inédita de licenciatura en historia). Universidad de Valparaíso, Valparaíso. (2003). El paraíso perdido. Werken, 3, 41-55.

Hito, S. (2004). VAAI HANGA KAINGA giving care to the motherland: Conflicting narratives of Rapanui. Journal of Intercultural Studies, 25(1), 21-34.

Hau'ofa, E. (1994). Our sea of islands. The Contemporary Pacific, 6(1), 147-161.

International Work Group for Indigenous Affairs. (2012). Los derechos humanos del pueblo rapa nui en Isla de Pascua. Informe de Misión de Observadores a Rapa Nui 2011. Informe IWGIA 15. Observatorio Ciudadano, Santiago.

Keesing, R. M. (2000). Creating the past: Custom and identity in the contemporary Pacific. En Hanlon, D. \& White, G. M. (Eds.)., Voyaging through the contemporary Pacific (pp. 231-254). Oxford: Rowman \& Littlefield Publishers.

Lagos, X. \& Escobar, B. (2009). Voces del Pacífico: Una comunidad en busca del reconocimiento autonómico. (Tesis inédita de licenciatura en antropología). Universidad Académica de Humanismo Cristiano, Santiago.

Mawyer, A. \& Jacka, J. K. (2018). Sovereignty, conservation, and island ecological futures, 45(3), 238-251. doi: https://doi.org/10.1017/ S037689291800019X.

Mazé, C., Dahou, T., Ragueneau, O., Danto, A., Mariat-Roy, E. \& Raimonet, M. (2017). Knowledge and power in integrated coastal management: For a political anthropology of the sea combined with the marine environment sciences. Comptes Rendus Geoscience, 349(6-7), 359-368. doi: https://doi.org/10.1016/j.crte.2017.09.008.

Mendoza, O. (2004). Chile: un país colonialista: El Tratado Internacional de 1888 entre Chile y Rapanui. Simposio Rapa Nui a 116 años de la "Anexión". En Actas V Congreso Chileno de Antropología, Tomo II (pp. 1290-1299), San Felipe. Recuperado de https://www. aacademica.org/v.congreso.chileno.de.antropologia/170.

McCall, G. (1996). El pasado en el presente de Rapanui (Isla de Pascua). En Hidalgo, J., Schiappacasse, V., Niemeyer, H., Aldunate, C. \& Mege, P. (Eds.), Etnografía: Sociedades indígenas contemporáneas y su ideología (pp. 17-46). Santiago: Andrés Bello.

MMA (Ministerio de Medio Ambiente) (2017). Informe del Proceso de Consulta al pueblo Rapa Nui sobre creación, administración y regulación de usos de un Área Marina Costera Protegida de Múltiples Usos para Rapa Nui: Informe Comuna y Provincia de Isla de Pascua Pueblo Rapa Nui. Ministerio del Medio Ambiente, septiembre.

OCEANA (2011). Informe científico: Expedición a Isla de Pascua y Sala y Gómez. Febrero-marzo.

Oyanedel, R., Marín, A., Castilla, J. C. \& Gelcich, S. (2016). Establishing marine protected areas through bottom-up processes: Insights from two contrasting initiatives in Chile. Aquatic Conservation: Marine and Freshwater Ecosystems, 26(1), 184-195. doi: https://doi. org/10.1002/aqc.2546.

Pahl-Wostl, C. (2009). A conceptual framework for analyzing adaptive capacity and multi-level learning processes in resource governance regimes. Global Environmental Change, 19 (3), 354-365. doi: http://dx.doi.org/10.1016/j.gloenvcha.2009.06.001

Paredes, F., Flores, D., Figueroa, A., Gaymer, C. \& Aburto, J. (2019). Science, capacity building and conservation knowledge the: The empowerment of the local community for marine conservation in Rapa Nui. Aquatic Conservation: Marine and Freshwater Ecosystems, 29(2), 130-137. doi: https://doi.org/10.1002/aqc.3114

Pressey, R. L., Cabeza, M., Watts, M. E., Cowling, R. M. \& Wilson, K. A. (2007). Conservation planning in a changing world. Trends in Ecology and Evolution, 22(11), 583-592. 
Sahlins, M. (1997) Islas de historia: La muerte del capitán Cook: Metáfora, antropología e historia. Barcelona: Gedisa.

Santos, C. (2010). ¿Qué protegen las áreas protegidas?: Conservación, producción, Estado y sociedad en la implementación del Sistema Nacional de Áreas Protegidas de Uruguay. Los Polvorines: Instituto de Desarrollo Económico y Social, Universidad Nacional General Sarmiento.

Secretaría del Convenio sobre la Diversidad Biológica (2004). Programa de Trabajo sobre Áreas Protegidas (Programas de trabajo del CDB). Secretaría del Convenio sobre la Diversidad Biológica, Montreal.

Stambuk, P. (2010). Rongo: La historia oculta de Isla de Pascua. Santiago: Pehuén.

Stavenhaggen, R. (2004). Informe del Relator Especial sobre la situación de los derechos humanos y las libertades fundamentales de los indígenas sobre su visita a Chile. Recuperado de http://www. derechos.org/nizkor/chile/doc/staven2.html.
Tcherkézoff, S. (1997). Le mana, le fait "total" et "'esprit" dans la chose donnée : Marcel Mauss, les "cadeux à Samoa" et la méthode comparative en Polynésie. Anthropologie et Sociétés, 21(2-3), 193-223.

(2004). On the boat of Tangaroa. En Tcherkézoff, S., Humanity and divinity in Polynesian-European first contacts: $A$ reconsideration (pp. 113-158). Canberra: Australian National University Press. Recuperado de http://epress.anu.edu.au/first_contacts citation. html.

Ther-Ríos, F. (2012). Antropología del territorio. Polis, 11(32), 493- 510. http://dx.doi.org/10.4067/S0718-65682012000200023

West, P., Igoe, J. \& Brockington, D. (2006). Parks and peoples: The social impact of protected areas. Annual Review of Anthropology, (35), 251-277.

Zurbriggen, C. (2011). Gobernanza: una mirada desde América Latina. Perfiles Latinoamericanos, (38), 39-64. 